\title{
A IMPORTÂNCIA DO TRABALHO DE MIRANDA MAGNOLI NAS EXPERIÊNCIAS DE PESQUISA SOBRE ARQUITETURA DA PAISAGEM NA FAU-UFRJ
}

THE IMPORTANCE OF PROF. MIRANDA MAGNOLI'S WORK IN THE RESEARCH EXPERIENCES IN LANDSCAPE ARCHITECTURE DESIGN DEVELOPED IN FAU-UFRJ 


\title{
RESUMO
}

O objetivo deste artigo é relacionar a importância dos conceitos emanados do trabalho da professora Miranda Martinelli Magnoli para a formação de um corpo de pesquisa sobre arquitetura da paisagem, a partir de 2000, no Programa de Pós-Graduação em Arquitetura da FAU-UFRJ. Utilizando como referência as dissertações de mestrado e teses de doutorado produzidas e em produção pelo ProArq, pretende-se salientar o peso da reflexão crítica, profunda e sistemática que a professora Magnoli impõe ao seu trabaIho, como professora e pesquisadora da pós-graduação da FAUUSP, na qual a autora desenvolveu sua tese de doutorado e seus principais reflexos nas atividades didáticas na graduação e na pós-graduação da FAU-UFRJ.

Palavras-chave: Ensino, pesquisa, espaços livres.

\begin{abstract}
This article aims to relate the importance of the ideas and concepts generated by Prof. Miranda Martinelli Magnoli and used in the composition of a research field about landscape architecture design, since 2000, in the Graduate Program in Architecture-PROARQ of the School of Architecture and Urbanism-FAU of the Federal University of Rio de Janeiro-UFRJ. Taking as examples several Master and Doctorate dissertations and thesis of $P R O A R Q$, the purpose is to point out the role played by the critical, deep and systematic discussion applied by Prof. Magnoli in her work, in the Graduate Program of the School of Architecture and UrbanismFAU of the University of São Paulo-USP, where the author developed her Doctorate thesis, focusing on the main consequences in the teaching activities in the undergraduate and graduate classes in the FAU-UFRJ.
\end{abstract}

Key words: Education, research, open space. 


\title{
A IMPORTÂNCIA DO TRABALHO DE MIRANDA MAGNOLI NAS EXPERIÊNCIAS DE PESQUISA SOBRE ARQUITETURA DA PAISAGEM NA FAU-UFRJ
}

\author{
THE IMPORTANCE OF PROF. MIRANDA MAGNOLI'S \\ WORK IN THE RESEARCH EXPERIENCES IN LANDSCAPE \\ ARCHITECTURE DESIGN DEVELOPED IN FAU-UFRJ
}

\section{Antecedentes}

O primeiro contato que tive com o trabalho da professora Miranda Martinelli Magnoli foi quando, ao iniciar o curso de doutorado na FAUUSP em setembro de 1994, tendo o professor Silvio Soares Macedo como orientador, li os artigos publicados por esses dois professores no III Seminário sobre Desenho Urbano - SEDUR, realizado em 1986'.

Nessa ocasião, eu havia ingressado recentemente no quadro de docentes da FAU-UFRJ e, com os professores Mario Ceniquel e Lucia Costa, estávamos reestruturando as disciplinas de Paisagismo na graduação da FAU-UFRJ.

De todas as idéias e conceitos estudados nessas primeiras leituras, as referências sobre "espaços livres de edificação" e "espaços livres de urbanização" tiveram grande impacto naquele momento sobre a definição do campo teórico disciplinar sobre o qual se constituiria minha experiência como professora e pesquisadora da FAU-UFRJ.

No desenvolvimento do projeto de pesquisa para o doutorado, a leitura da tese de livre-docência da professora Miranda defendida também na FAUUSP2, completou esse arcabouço conceitual que, devido à minha experiência com a disciplina de Desenho Urbano no mestrado e na prática profissional ${ }^{3}$, refletem de uma forma mais completa a linha a qual busco seguir em meu próprio trabalho.

O contato com a professora Magnoli intensificou-se após cursar sua disciplina: A Paisagem no Desenho do Cotidiano, cujos apontamentos se transformaram em uma importante introdução à revisão histórica sobre o conceito de espaços livres de edificação e urbanização nas cidades ocidentais, tornando-se referencial sobre pesquisas posteriores que desenvolvi no doutorado, refletidas na monografia desenvolvida para sua disciplina e em artigo publicado na revista Paisagem e Ambiente ${ }^{4}$.

Finalmente a presença da professora Miranda em minhas bancas de qualificação, em 1998, e de defesa final de tese de doutorado, em $2000^{5}$, refletiu não apenas sua importância para a consolidação de minha base de pesquisa, desenvolvida na FAUUSP, como também a influência de seu pensamento e análise crítica nos conceitos que eu viria a adotar dali para frente, na graduação e na pós-graduação da FAU-UFRJ. 


\section{Os Conceitos e Idéias Sobre os Espaços Livres Aplicados na FAU-UFRJ}

Após a defesa de tese de doutoramento, a aplicação dos conceitos emanados das discussões e reflexões acima descritos se rebateu nas atividades que exerço na pós-graduação e na graduação da FAU-UFRJ, a partir de orientações de dissertações de mestrado e, mais recentemente, de doutorado e por meio de disciplinas de Projeto de Arquitetura e Projeto Paisagístico.

\section{A Experiência na Pós-Graduação}

Criada a partir da reformulação do Programa de Mestrado em Arquitetura - PROARQ, coordenada pelo Prof. Dr. Vicente Del Rio, a linha de pesquisa intitulada Arquitetura e Lugar, desenvolvida dentro da antiga área de concentração em Teoria e Projeto, contou com a colaboração de demais docentes da FAU-UFRJ, entre eles, o Prof. Dr. Mario Ceniquel, o Prof. Dr. Paulo Afonso e a Profa. Dra. Cristiane Duarte.

Essa linha busca aprofundar a integração entre campos de pesquisa relacionados ao ensino e pesquisa em arquitetura, principalmente desenho urbano e paisagem urbana, e uma de suas características é o aprofundamento da conceituação sobre os sistemas de espaços livres urbanos, analisados sob o viés da análise morfológica da paisagem e seus desdobramentos. Os resultados têm gerado publicações, participação e organização de seminários e congressos e de atividades didáticas especiais, tais como oficinas de ensino e seminários.

Dentro dessa linha, a disciplina Arquitetura da Paisagem, desenvolvida desde 2001, reflete sobre a avaliação crítica da produção da paisagem na escala urbana, considerando o acelerado processo de transformação das cidades brasileiras. São discutidos os agentes de transformação da paisagem, dentro de uma perspectiva histórica, os padrões de morfologia da paisagem e de apropriação dos espaços públicos normalmente encontrados nos espaços livres das cidades brasileiras e a influência das formas de parcelamento e da legislação urbanística em sua configuração.

Essa disciplina tem gerado a publicação de artigos elaborados por alunos da pós-graduação que utilizaram os métodos de análise propostos para a disciplina aplicados aos espaços urbanos, objeto de suas pesquisas ${ }^{6}$.

Entretanto, a melhor avaliação dessa produção e das influências dos conceitos sobre espaços livres oriundos do trabalho da professora Magnoli deve ser feita pelas dissertações elaboradas sob minha orientação, dentre as quais se destacam:

a) Dissertações defendidas:

LONDON, Marcos Z. "A circulação de idéias urbanísticas no meio profissional e acadêmico e sua influência nas obras de Donalt Alfred Agache e Attílio Corrêa Lima". Defendida em 27/3/2002. Rio de Janeiro. PROARQ/FAU/UFRJ, 2002.

ANDRADE, Rubens. "Antonio Lemos e as obras de melhoramentos urbanos em Belém". Defendida em 30/1/2003. Rio de Janeiro. PROARQ/FAU/UFRJ, 2003.

SANTUCCI, Jane. "As promenades do Rio de Janeiro: $O$ papel do Passeio Público, Praça Paris e Aterro do Flamengo na história da paisagem carioca". Defendida em 29/1/2003. Rio de Janeiro. PROARQ/FAU/UFRJ, 2003.

EPPINGHAUS, Annie Goldberg. "Influência do projeto no processo de apropriação dos espaços públicos em áreas residenciais: $\bigcirc$ caso da Barra da Tijuca". Defendida em 28/4/2004. Rio de Janeiro. PROARQ/FAU/UFRJ, 2004.

SANTOS, Eloísa. "O paisagismo de Burle Marx e a moderna arquitetura brasileira". Defendida em 28/4/2004. Rio de Janeiro. PROARQ/FAU/UFRJ, 2004. 
ABREU, Luciano Muniz. "Territórios turísticos e o desenho da paisagem urbana litorânea no nordeste brasileiro: Uma análise de projetos de urbanização financiados no âmbito do Programa de Desenvolvimento do Turismo no Nordeste do Brasil-PRODETUR/NE". Defendida em 27/4/2005. Rio de Janeiro. PROARQ/FAU/UFRJ, 2005.

MAMBRINI, Natalia. "Evolução ambiental na Barra da Tijuca: $O$ sistema de espaços livres no entorno da Lagoa da Tijuca". Defendida em 27/4/2005. Rio de Janeiro. PROARQ/FAU/UFRJ, 2005.

b) Dissertações em andamento:

AMORIM, Flavia. "Os condomínios fechados na Barra da Tijuca, no Rio de Janeiro, e os condomínios fechados do Bairro Belvedere III, em Belo Horizonte: Um estudo comparativo". PROARQ/FAU/UFRJ. Iniciada em 2005.

BRAGA, Flavia T. "A produção da paisagem dos espaços livres residenciais na Barra da Tijuca e Região Oceânica de Niterói: Um estudo comparativo de casos". PROARQ/FAU/UFRJ. Iniciada em 2006.

\section{A Experiência na Graduação}

Na graduação, o caráter interdisciplinar desenvolvido nas disciplinas de Paisagismo baseia-se na integração às temáticas gerais selecionadas para os ateliês de Projeto de Arquitetura e de Paisagismo, aproximando métodos, mas resguardando enfoques e objetos de intervenção.

Mais especificamente, a disciplina Paisagismo II pretende discutir, em seu conteúdo, questões relacionadas com o projeto e a análise da paisagem urbana, com ênfase nos seguintes temas: morfologia da paisagem urbana; morfologia dos espaços livres urbanos, e linhas projetuais contemporâneas. Foi desenvolvida em conjunto com as professoras Márcia Menneh, doutora pela FAUUSP, e Ivete Farah, docente da FAUUFRJ.

Busca-se, como objetivos específicos, a discussão integrada entre o volume edificado e o nãoedificado, nos quais se destacam questões paisagísticas, ambientais e urbanísticas envolvidas nessa integração, desde o parcelamento do solo ao tratamento específico dos espaços livres.

Finalmente, em duas outras atividades didáticas da graduação, fazem-se presentes os conceitos sobre espaços livres de edificação: na orientação de graduandos para a elaboração, em terma livre, dos Trabalhos Finais de Graduação (TFG), e no desenvolvimento de oficinas didáticas especiais.

Em 2001, foi realizada a I Oficina Arquitetura da Paisagem, com o tema "Revitalização Paisagística e Funcional dos Pátios Internos do Palácio Universitário, no Campus da Praia Vermelha - UFRJ", sendo uma atividade de extensão conjunta promovida pelo Instituto de Economia e Faculdade de Arquitetura e Urbanismo ${ }^{7}$.

Em 2005, foi realizada a II Oficina Arquitetura da Paisagem, sobre a metodologia do Projeto Orla do Ministério do Meio Ambiente aplicada à Ilha do Fundão, na Cidade Universitária da UFRJ, sendo também uma atividade de extensão conjunta promovida pelo Escritório Técnico da Universidade-ETU e pela Faculdade de Arquitetura e Urbanismo ${ }^{8}$.

\section{Reflexões e Desdobramentos}

A partir de uma proposta formulada pela FAUUSP de projeto de pesquisa integrado, coordenado pelo professor Silvio Macedo, estruturou-se na FAU-UFRJ um trabalho de avaliação sistêmica do sistema de espaços livres públicos da cidade do Rio de Janeiro. 
Essa análise deverá será feita sobre recortes específicos do território, entendidos como componentes de um outro sistema ainda maior, no que se refere à escala territorial ou à complexidade das dinâmicas socioeconômicas encontradas localmente.

Como estudo-piloto, pretende-se aplicar a pesquisa, inicialmente, aos principais espaços livres e áreas verdes existentes na região de São Cristóvão, a partir de uma parceria com a prefeitura da cidade do Rio de Janeiro, onde, como modelo teórico, objetiva-se enfocar a inserção hierárquica no tecido urbano, conforme a escala de abrangência, os atributos (físicos e psicológicos), os tipos, a origem histórica e os modelos de projeto.

Após a conclusão desse estudo-piloto, pretende-se aplicar a análise para outras regiões da cidade, com intuito de montar uma base de análise confiável que poderá auxiliar o planejamento estratégico do sistema de espaços livres na escala da cidade, tendo sempre como premissa a importância da reflexão crítica e prospectiva sobre o sistema de espaços livres públicos urbanos, preconizados pela professora Magnoli.

\section{Notas}

(1) Ver MAGNOLI, Miranda. O parque no desenho urbano. MACEDO, Silvio. Espaços livres de edificação e o desenho da paisagem urbana. In: TURKIENICZ, Benamy e MALTA, Maurício. Anais do II SEDUR. São Paulo, CNPq/ Finep/Pini, 1986.

(2) Ver MAGNOLI, Miranda M. Espaços livres e urbanização - Uma introdução aos aspectos da paisagem metropolitana. Tese de livre-docência, São Paulo, FAUUSP, 1982.

(3) Meu curso de mestrado em planejamento urbano foi realizado na University of Michigan, tendo como área de concentração Urban Design, e, como dissertação, o trabalho intitulado "Barra da corda: Uma comunidade rural no Brasil". A partir de 1986, as minhas experiências profissionais estiveram relacionadas a estudos e projetos de paisagismo e urbanização e a projetos na área de desenho urbano, destacando-se, a partir de 1993, o conjunto de trabalhos realizados: no escopo do Projeto RioCidade para a prefeitura da cidade do Rio de Janeiro, para os bairros: Méier, eixo da avenida Suburbana (Benfica a Pilares), Irajá, eixo da avenida Santa Cruz (Bangu a Campo Grande) e área portuária (Saúde, Gamboa, Santo Cristo); e no escopo da SP-Trans, para a Prefeitura Municipal de São Paulo, tais como o corredor avenida lbirapuera e o corredor Tiradentes.

(4) A monografia intitulada "Os espaços livres urbanos e o processo de urbanização: $O$ caso do Méier", apresentada em fevereiro de 1995, deu origem a dois artigos publicados na Revista Paisagem Ambiente - Ensaios: TÂNGARI, Vera Regina. Da avenida Central ao Rio Cidade, o Rio de Janeiro constrói e reconstrói a sua imagem. Paisagem e Ambiente - Ensaios, São Paulo: FAUUSP, n. 9, p. 151-176, 1998 e TÂNGARI, Vera Regina. Paisagem urbana na zona norte do Rio - O caso do Méier. Paisagem e Ambiente - Ensaios, São Paulo: FAUUSP, n. 8, p. 47-66, 1996.

(5) TÂNGARI, Vera. Um outro lado do Rio. Tese de doutorado, São Paulo, FAUUSP, 1999.

(6) SANTANA, Ethel P.; TÂNGARI, Vera Regina. Espaço arquitetônico x Apropriação: Estudo de Caso no Centro do Rio de Janeiro-Largo da Carioca e Rua Uruguaiana. Paisagem e Ambiente - Ensaios, São Paulo: FAUUSP, n. 17, p. 43-68, 2003; ANDRADE, Rubens e TÂNGARI, Vera Regina. A Praça da República e seus aspectos morfológicos no Desenho da Paisagem de Belém. Paisagem e Ambiente - Ensaios, São Paulo: FAUUSP, n. 16, p. 43-68, 2003; POPPE, Marcia e TÂNGARI, Vera Regina. O centro de comércio e serviços Downtown na Barra da Tijuca: Entre a cidade existente e a fragmentação do espaço urbano. In: Anais do VII Encontro Nacionalde Ensino e Paisagismo em Escolas de Arquitetura e Urbanismo no Brasil - UFMG: Belo Horizonte, 2004. CD-ROM.

(7) Ver FAU-UFRJ. Revista Academia, vol. 4. Rio de Janeiro: FAU-UFRJ, 2003.

(8) Ver TÂNGARI, Vera; SCHLEE Mônica Bahia e ANDRADE, Rubens de. Anais do I Seminário Nacional sobre Regeneração Ambiental de Cidades - Águas Urbanas. CD-ROM. FAU-UFRJ, 2005.

\section{Bibliografia}

MACEDO, Silvio S. Paisagem urbana - Introduzindo questões. 1997. Trabalho apresentado ao I Encontro Mineiro para Conservação da Natureza - Universidade Federal de Viçosa, Viçosa/MG, set./1997.

118 . Paisagem, urbanização e litoral - Do éden à cidade. 1993. Tese (Livre-docência) - Faculdade de Arquitetura e Urbanismo, Universidade de São Paulo, São Paulo, 1993.

Espaços livres de edificação e o desenho da paisagem urbana. In: TURKIENICZ, Benamy; MALTA, Maurício. Anais do II SEDUR. São Paulo: CNPq/Finep/Pini, 1986. 
MACEDO, Silvio Macedo; CENIQUEL. O paisagismo no Brasil - Introduzindo a questão. Paisagem e Ambiente: Ensaios, São Paulo: FAUUSP, n. 4, 1992.

MAGNOLI, Miranda. O parque no desenho urbano. In: TURKIENICZ, Benamy; MALTA, Maurício. Anais do II SEDUR. São Paulo: CNPq/Finep/Pini, 1986.

. Espaços livres e urbanização - Uma introdução aos aspectos da paisagem metropolitana. 1982. Tese (Livre-docên$\overline{c i a)}$ - Faculdade de Arquitetura e Urbanismo, Universidade de São Paulo, São Paulo, 1982.

MENNEH, Marcia. Morfologia da paisagem verticalizada: Conflitos e padrões urbanísticos. 1997. Dissertação (Mestrado) - Faculdade de Arquitetura e Urbanismo, Universidade de São Paulo, São Paulo, 1997.

TÂNGARI, Vera. Os projetos de espaços públicos no Rio de Janeiro e a visão da mídia. 1998. Trabalho programado (Memorial de qualificação) - Faculdade de Arquitetura e Urbanismo, Universidade de São Paulo, São Paulo, 1998. $\overline{1996 .}$

Paisagem uma zona norte do Rio: $O$ caso do Méier. Paisagem e Ambiente: Ensaios, São Paulo: FAUUSP, n. 8,

. Um outro lado do Rio. 1999. Tese (Doutorado) - Faculdade de Arquitetura e Urbanismo, Universidade de São Paulo, São Paulo, 1999. 